\title{
Household Savings in South Africa: An Econometric Analysis
}

\author{
Itumeleng Pleasure Mongale \\ Department of Economics, Faculty of Commerce and Administration, \\ North-West University (Mafikeng Campus), South Africa \\ E-mail: itumeleng.mongale@nwu.ac.za \\ Janine Mukuddem-Petersen \\ Graduate School of Business and Government Leadership, Faculty of Commerce and Administration, \\ North-West University (Mafikeng Campus), South Africa \\ E-mail: Janine.MukuddemPetersen@nwu.ac.za \\ Mark A. Petersen \\ Faculty of Commerce and Administration, \\ North-West University (Mafikeng Campus), South Africa \\ E-mail: Mark.Petersen@nwu.ac.za

\section{Christelle Meniago} \\ Department of Economics, Faculty of Commerce and Administration, \\ North-West University (Mafikeng Campus), South Africa \\ E-mail: christalpiece@yahoo.fr
}

Doi:10.5901/mjss.2013.v4n13p519

\begin{abstract}
This paper examines the determinants of household savings in South Africa by utilizing time series data from the South African Reserve Bank. The household savings model is estimated by using the cointegrating vector autoregressive (CVAR) framework. To check robustness on the cointegration results, we employ generalized impulse response function (GIRF) analysis and variance decomposition. The findings show that all the variables have unit roots and cointegration emphasizes the presence of a long run equilibrium relationship. The results indicate that household savings is mainly influenced by a high level of household debt.
\end{abstract}

Keywords: Household savings; Cointegrated vector autoregression; Generalized impulse response function; variance decomposition; South Africa.

\section{Introduction/Background/ Rationale}

Compared to some of its BRICS ${ }^{1}$ counterparts, South Africa's 15\% saving ratio is low. The saving ratio of India is in the region of $30 \%$. China has had by far the highest overall saving rate in the world since 2000 . Its saving rate has increased even further since, to nearly $50 \%$ of GDP. Gross capital formation (investment) is also high in China, but because saving exceeds investment, it is running a net surplus which translates into a current account surplus (Horioka and Wan, 2007). These rapidly growing economies have clearly benefitted from a robust savings environment. As alluded earlier, South Africa had a national savings rate of about $15 \%$ before the Global Financial Crisis. The national savings rate includes household, corporate, public services and government savings in South Africa. In essence, according to McLvor (2009), the aforementioned national savings rate is low by international standards. Savings as a percentage of GDP is 15\% versus $34 \%$ in other developing countries and $34 \%$ worldwide.

The South African Reserve Bank (SARB,2010) indicates that the national savings rate deteriorated from a high of $17.5 \%$ in the final quarter of 2002 to a low of $12.9 \%$ in the third quarter of 2007 as consumption expenditure increased.

1It is an acronym referring to a grouping of emerging economies which include Brazil, Russia, India, China \& South Africa. 
The contra-cyclical expansionary fiscal policy adopted by general government increased government's recurrent expenditure, while the recessionary conditions adversely affected income. The household savings ratio improved from $1.0 \%$ in the first half of 2008 to $1.7 \%$ in the second half of 2009 , mainly reflecting a decline in household expenditure over this period. Strict lending criteria and uncertainties brought about by the financial crisis contributed to a more cautious approach to spending (SARB, 2010).

With its large structural savings/investment gap, South Africa depends on foreign savings to support investment and growth (Bureau of Economic and Business Affairs U.S. Department of State, 2002). The types of savings available do not easily make financial intermediation possible (Aryeetey, 2004). According to Allen and Giovannetti (2010), improved levels of household savings will contribute to domestic resources, which will act as a mitigating factor against financial crises. The right response to the crisis would be to mobilise domestic resources, although this will require that functional institutions should offset the potential trade-offs between the short term shocks and long term perspective.

This study appears to be the first of its kind to consider an econometric analysis of household savings in South Africa and also the first one to investigate this matter using the CVAR model to estimate the relationship between household savings and its determinants. Furthermore, it is definitely the first to analyse this problem by employing the GIRF and variance decomposition analyses.

Ultimately, this novel econometric study attempts to contribute to the literary body of knowledge by exploring the econometric analysis of household savings (from 1994 to 2011) in the South African economy as well as examining the imbalances in savings and consumption.

The remainder of the paper is organized as follows: Section 2 provides the data source, definition of variables, objectives, methodology and results and Section 3 concludes the paper.

\section{Data, Objectives, Methodology and Results}

\subsection{Data and Objectives}

This study uses a model that includes time series variables and the data (1994Q1 to 2011Q4) is obtained from the SARB. However, due to different frequencies, some data needed to be attuned before use, to form a homogenous quarterly data set (see Appendix 1). In this regard, the quarterly data offers several advantages over studies that employ annual variables and also allows intra-year dynamics.

The objective of this paper is to utilize time series data to run regressions in identifying the determinants that affect household savings in the South African economy. Then we employ the Generalized Impulse Response Function (GIRF) to examine dynamic relationships among the variables. Finally, we conduct the variance decomposition analysis to evaluate which variables mostly contribute in explaining the shocks in household savings.

\subsection{Methodology and Results}

The CVAR used in this study was developed by Johansen and Juselius (1990). The choice of this method is influenced by Trygve Haavelmo's "The Probability Approach in Econometrics" which focuses on obtaining good characterization of data before testing and on drawing out the implications of data that ought to constrain economic theorizing (Haavelmo, 1944). This model provides a multivariate framework where changes in a particular variable are related to changes in its own lags and to changes in other variables. All variables are treated as endogenous and do not impose priori restrictions on the structural relationships (Aktham, 2004). It can also be construed as a combination of a VAR model and a vector error correction model (VECM). A VEC model is a special form of the VAR for the I(1) variables which are cointegrated (Griffiths et al. 2008).

The CVAR is different from other approaches such as the London School of Economics (LSE) approach which has most often focused on single equations. The approach can be distinguished from many other applications for cointegration in systems of equations by its focus on well-specified, congruent statistical models, a hallmark of Haavelmo's probability approach (Hoover et al., 2008). The single equation representations assume the existence of at most a single cointegrating relationship and do not take into account the possible endogeneity of explanatory variables. Kulshreshtha and Parikh (2000) maintain that the single equation framework is estimated under the highly restrictive assumption that any disequilibrium would be corrected by only one variable (independent variable), which will adjust in a 
direction, opposite to that of disequilibrium². This limitation is overcome in the CVAR approach, which allows a number of variables to adjust and respond at different rates to disturbances in a way that the system converges to long run equilibrium. Specifically this CVAR methodology will enable us to estimate the correlation between household savings and the following dependent variables: household disposable income, household indebtedness, real GDP growth rates, foreign savings, inflation and interest rates. As alluded to earlier, we will analyze the long-run and short-run relationship between household savings and its main determinants during the period 1994 to 2010.

Tiwari (2011) maintains that before conducting static and dynamic analysis certain pre-estimations like unit root and cointegration are required because without them conclusions drawn from this study may not be valid. Unit root testing should be seen as a mandatory exercise to be carried out prior to modeling as it is crucial to think about the dynamic variables and data that measure them before estimating and forecasting the model (Mahadeva and Robinson, 2004). Pradhan (2009) maintains that unit root test is meant to know the stationarity of the variables. Such variables might have a spurious regression where the $\mathrm{R}^{2}$ looks great and t-statistics are significant, but the results may have no meaning because the estimates are not consistent. Therefore, we need to have a stationary dataset. The number of unit roots in a series is the same as the number of times the concerned variable is to be differenced from its lagged values to attain stationarity. This means that a particular time series $\left(\mathrm{Y}_{\mathrm{t}}\right)$, that contains a single unit root is nonstationary in the level or original form. When it is then differenced, that is, when

$$
\Delta Y_{t}=Y_{t}+Y_{t-1}
$$

is generated, the resulting series therefore becomes stationary (Rufino, 2008).

There are a string of unit root tests designed to render a verdict as to whether a given time series data appears to imply the presence of a unit root or whether it should be considered to be stationary (Elliot, Rothenberg, and Stock, 1996; Dickey and Fuller, 1979; Kwiatkowski et al. 1992; Ng and Perron, 2001 and Phillips and Perron, 1998). In this paper, we selected ADF, PP and KPSS tests and considered them sufficient to explore the dynamics of the series by empirically verifying the stationarity of all the variables used in this study. Prior to performing these tests, the variables will first be transformed into logarithms to help avoid the problem of serial correlation and heteroskedasticity.

The results of the unit root tests in Table 1 (performed with intercept) indicate the robustness of the three tests with the exception of only one variables (LFSAV) which could not give the same results under KPSS test. This indicates that there may be a doubt as to the properties of the data or it might be the question of low power of both ADF and PP unit root tests with a root close to nonstationary boundary. All the results indicate a rejection of the null hypothesis of nonstationarity.

Table 1. Unit Root Analysis

\begin{tabular}{|c|c|c|c|c|c|c|}
\hline \multirow{2}{*}{ Variables } & \multicolumn{2}{|c|}{ ADF } & \multicolumn{2}{|c|}{ PP } & \multicolumn{2}{|c|}{ KPSS } \\
\hline & Levels & $1^{\text {st }}$ Difference & Levels & $1^{\text {st }}$ Difference & Levels & $1^{\text {st }}$ Difference \\
\hline LHSAV & $\begin{array}{l}-1.231560 \\
(-2.906923)\end{array}$ & $\begin{array}{l}-12.34648^{*} \\
(-2.905519)\end{array}$ & $\begin{array}{l}-1.19081 \\
(-2.904198)\end{array}$ & $\begin{array}{l}-11.89806^{*} \\
(-2.904848)\end{array}$ & $\begin{array}{l}0.848776 \\
(0.463000)\end{array}$ & $\begin{array}{l}0.095158 \\
(0.463000)\end{array}$ \\
\hline$L H Y D$ & $\begin{array}{l}-1.420195 \\
(-2.904198)\end{array}$ & $\begin{array}{l}-8.676087^{*} \\
(-2.904848)\end{array}$ & $\begin{array}{l}-1.481153 \\
(-2.904198)\end{array}$ & $\begin{array}{l}-8.707787^{*} \\
(-2.904848)\end{array}$ & $\begin{array}{l}1.108665 \\
(0.463000)\end{array}$ & $\begin{array}{l}0.253103 \\
(0.463000)\end{array}$ \\
\hline LHDE BT & $\begin{array}{l}-2.066551 \\
(-2.906923)\end{array}$ & $\begin{array}{l}-6.451452^{*} \\
(-2.904848)\end{array}$ & $\begin{array}{l}-0.834578 \\
(-2.904198)\end{array}$ & $\begin{array}{l}-6.550466^{*} \\
(-2.904848)\end{array}$ & $\begin{array}{l}0.669601 \\
(0.463000)\end{array}$ & $\begin{array}{l}0.14388 \\
(0.463000)\end{array}$ \\
\hline LRGDP & $\begin{array}{l}-0.335867 \\
(-2.904848)\end{array}$ & $\begin{array}{l}-4.995703^{*} \\
(-2.904848)\end{array}$ & $\begin{array}{l}-0.363158 \\
(-2.904198)\end{array}$ & $\begin{array}{l}-4.955158^{*} \\
(-2.904848)\end{array}$ & $\begin{array}{l}1.096448 \\
(0.463000)\end{array}$ & $\begin{array}{l}0.127971 \\
(0.463000)\end{array}$ \\
\hline LINTR & $\begin{array}{l}-1.431463 \\
(-2.904848)\end{array}$ & $\begin{array}{l}-4.834850^{*} \\
(-2.904848)\end{array}$ & $\begin{array}{l}-0.915091 \\
(-2.904198)\end{array}$ & $\begin{array}{l}-4.747167 * \\
(-2.904848)\end{array}$ & $\begin{array}{l}0.793110 \\
(0.463000)\end{array}$ & $\begin{array}{l}0.125916 \\
(0.463000)\end{array}$ \\
\hline LINFR & $\begin{array}{l}-4.356067 \\
(-2.904848)\end{array}$ & $\begin{array}{l}-5.900707^{*} \\
(-2.907660)\end{array}$ & $\begin{array}{l}-2.981672 \\
(-2.904198)\end{array}$ & $\begin{array}{l}-4.215836^{*} \\
(-2.904848)\end{array}$ & $\begin{array}{l}0.197910 \\
(0.463000)\end{array}$ & $\begin{array}{l}0.033585 \\
(0.463000)\end{array}$ \\
\hline LFSAV & $\begin{array}{l}-4.639386 \\
(-2.904198)\end{array}$ & $\begin{array}{l}-10.21651^{*} \\
(-2.589907)\end{array}$ & $\begin{array}{l}-4.611691 \\
(-2.904198)\end{array}$ & $\begin{array}{l}-13.22663^{*} \\
(.2 .904848)\end{array}$ & $\begin{array}{l}0.531390 \\
(0.463000)\end{array}$ & $\begin{array}{l}0.104321 \\
(0.463000)\end{array}$ \\
\hline
\end{tabular}

Note: Critical values are in parenthesis at $5 \%$. The appropriate lag length was selected by adopting the Akaike Information Criteria (AIC) for ADF test and New-West automatic using Bartlett Kernel method for both PP and KPSS tests

Since it has been established that with the exception of LINFR all the variables are integrated in the first difference and we are interested in modeling a long run relationship between household savings and its regressors, cointegration test is

${ }^{2}$ According to Kulshreshtha, M. \& Parikh, J. K. (2000) this is equivalent to assuming that the other variables are weakly exogenous. 
an ideal instrument. Johansen and Juselius cointegration approach allows us to estimate the long run relationship between variables. The test uses two likelihood ratio test statistics; namely the trace statistic and the maximum eigenvalue statistic to determine the number of ' $r$ ' cointegrating vectors in a set of a series. These ratios can be used for testing vectors in a model and to determine the number of cointegrating vectors and provides estimates of these vectors together with estimates of the adjustment parameters. The trace test, tests the null hypothesis that the number of distinct cointegrating vectors is less than or equal to $r$ against the alternative. On the other hand, the maximum eigenvalue test, tests the null hypothesis of $r$ cointegrating vectors against $r+1$ cointegrating vectors. The presence of cointegration in the variables serves as evidence for the existence of a long run relationship.

Pradhan (2011) indicates that this method is more advanced and more powerful than the Engle and Granger method and the test is described as follows:

Let $X_{t}$ be a $(n \times 1)$ vector of variables with time period t and they follow I (1) process. The investigation of number of cointegrating vector involves the estimation of unrestricted VAR model.

$$
\Delta X_{t}=A_{0}+\Pi X_{t-p}+\sum_{i=1}^{p-1} A_{i} \Delta X_{t-i}+\epsilon_{t}
$$

where $\Pi$ is the impact matrix and contains information about long run relationships between variables in the data vector. If the rank of $\Pi$ (say, $r$ ) is equal to zero, the impact matrix is a null vector. Subsequently if $\Pi$ has a full rank, $n$, then the vector process $x_{t}$ is stationary. If $0<r<n$ then there exists $r$ cointegrating vector. The cointegrating rank, $r$, can be tested with two statistics.

If it happens that a different result comes up, the maximum eigenvalue test result should be preferred (Banerjee et al., 1993). They both reject the hypothesis that there are no cointegrating relationships among the variables. Verbeek (2004) indicates that the trace test checks whether the smallest $k$ - ro eigenvalues are significantly different from zero. The hypothesis $H_{0}: r \leq r 0$ versus $H_{1}: r_{0}<r \leq k$ can be tested by using the statistic

$$
\lambda_{\text {trace }}\left(r_{0}\right)=-T \sum_{j=r_{0}+1}^{k} \log \left(1-\hat{\lambda}_{j}\right)
$$

It is called the trace test because it is based on a likelihood ratio test about the trace of the matrix. As it is indicated above, the null hypothesis tested is that the number of cointegrating vectors is less than or equal to $r$, where $r$ is 0,1 or 2 and in each case the null hypothesis is tested against the general alternative. The maximum eigenvalue test is similar, except that the alternative hypothesis is explicit. The null hypothesis of $r=0$ is tested against $r=1$ and $r=1$ is tested against $r=2$ and so on (Dickey et al., 1991). The maximum eigenvalue test is based on the estimated $\left(r_{0}+1\right)$ th largest eigenvalue and we can test $H_{0}: r \leq r_{0}$ versus the more restrictive alternative $H_{1}: r=r_{0}+1$ by using

$$
\lambda_{\text {max }}\left(r_{0}\right)=-T \log \left(1-\hat{\lambda}_{j}\right)
$$

The null hypothesis in this case is that there is cointegrating vectors and that we have up to $r$ cointegrating relationships, whereas, the alternative hypothesis suggests that there is $(r+1)$ vectors. Furthermore, Asteriou and Hall (2009) point out that the maximum eigenvalue test statistics are based on the characteristic roots also called eigenvalues which are obtained from the estimation procedure. The test consists of ordering the largest eigenvalues in descending order and considering whether they are significantly different from zero.

The summary of the results of the cointegration test and the normalized vectors are presented in Table 2.

Table 2. Johansen Test for Cointegration

\begin{tabular}{|c|c|c|c|c|c|}
\hline \multicolumn{3}{|c|}{$\begin{array}{c}c \\
\text { A }\end{array}$} & \multicolumn{3}{c|}{ Trace test } \\
\hline Null hypothesis & Alternative hypothesis & Test statistic & Null hypothesis & Alternative hypothesis & Test statistic \\
\hline$r=0$ & $r=1$ & $68.59242 *$ & $r=0$ & $r \geq 1$ & $202.8492 *$ \\
\hline$r=1$ & $r=2$ & $42.82655 *$ & $r=1$ & $r \geq 2$ & $134.2568 *$ \\
\hline$r=2$ & $r=3$ & $36.75443 *$ & $r=2$ & $r \geq 3$ & $91.43023 *$ \\
\hline$r=3$ & $r=4$ & 24.34431 & $r=3$ & $r \geq 4$ & $54.67581 *$ \\
\hline$r=4$ & $r=5$ & 16.46615 & $r=4$ & $r \geq 5$ & $30.33149 *$ \\
\hline$r=5$ & $r=6$ & 12.39334 & $r=5$ & $r \geq 6$ & 13.86534 \\
\hline$r=6$ & $r=7$ & 1.472001 & $r=6$ & $r \geq 7$ & 1.472001 \\
\hline
\end{tabular}

Note: This table is mainly divided into two columns A and B. $r$ stands for the number of cointegrating vectors. $(*)$ Denotes rejection of the hypothesis at the 0.05 level 
In order to determine the number of cointegrating relations $r$, subject to the assumptions made about the trends in the series, the process can proceed sequentially from $r=0$ to $r=k-1$ until the study fails to reject. The first row of Table 2 tests the hypothesis of no cointegration and the second row tests the hypothesis of one cointegrating relation, the third row tests the hypothesis of two cointegrating relationship and so on. They are tested against the alternative hypotheses of full rank, that is, all series in the VAR are stationary. The trace test (column B) indicates that the null of no cointegration $(r=0)$ is rejected when tested against the alternative hypothesis of one cointegrating vector $(r \geq 1)$ since the test statistic of 202.8492 is greater than the $5 \%$ critical value of 125.6154 . The null hypothesis of one cointegrating vector $(r=1)$ is again rejected because test statistic of 134.2568 is greater than the $5 \%$ critical value of 95.75366 . The null hypothesis of two cointegrating vectors $(r=2)$ is also rejected because test statistic of 91.43023 is greater than the $5 \%$ critical value of 69.81889. Similarly the null of $r=3$ and $r=4$ are also rejected because their test statistics are greater than the $5 \%$ critical values. Therefore the null hypothesis is rejected at $5 \%$ level since the trace test indicates that there are 5 cointegrating equations at the same level.

Maximum eigenvalue (column A) test indicates the presence of 3 cointegrating equations at the $5 \%$ level for the household savings model. Since the trace and the maximum eigenvalue statics yeild different results, we therefore prefer the maximum eigenvalue results. As it has been established that cointegration exists amongst our variables; the next step is to use VECM and not VAR.

VECM is introduced to correct a disequilibrium that may shock the whole system and to study the interaction between the variables in the system. It also takes into consideration an additional channel of causation through the error correction mechanism (ECM) term (Hurley, 2010). The term is included to investigate the dynamic behavior of the model, that is, the dynamics of the short run and the long run.

Table 3. The Results of VECM Estimation

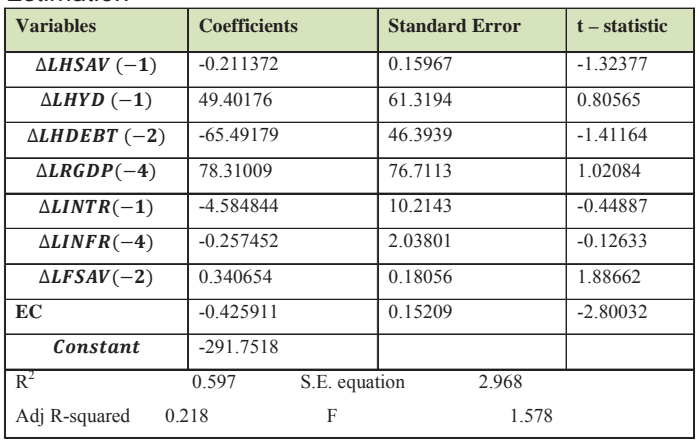

Notes: $\Delta$ : Denotes the first difference of the variables; R2: Coefficient of multiple determinations adjusted for the degrees of freedom (df)

The size of the error correction terms $(\mathrm{EC})$ indicates the speed of adjustment of any disequilibrium towards a long run equilibrium state (Adamopoulos, 2010). The estimated coefficient of EC of -0.425 in the equation in Table 3 is significant with the theoretically correct sign (negative sign) and a high absolute $t$-statistic of -2.80 . It is expected to be negative for equilibrium to be restored and it confirms that there is no problem in the long run equilibrium relationship between the dependent and the independent variables. The indication is that any short term fluctuations between the independent variables and the dependent variable will give rise to a stable long run relationship between the variables. This means that our error correction model is well specified and also confirms the findings on the cointegration of the variables. The estimated coefficient of -0.425 suggests that approximately $43 \%$ of the disequilibrium of the previous quarter comes back to long run equilibrium in the next quarter. The fact that ECM coefficient is significant and negative serves as evidence for the existence of cointegration relationship amongst the variables of the household saving function. It also points out to the presence of long term causal relations between the dependent variable and the independent variables.

The $\mathrm{R}^{2}$ of 0.597 in Table 3 indicates that approximately $60 \%$ of the variation in household savings is explained by the other macroeconomic variables. On the other hand, the remaining $40 \%$ can be explained by the omitted variables. The coefficient of changes in the previous period of household savings is positive and insignificant, showing that it may have a positive effect in the short term changes in savings for households. This implies that the saving decisions are based on previous behavior. The estimated coefficient of household disposable income is positive and significant. This 
indicates the importance of the level of income on the influence of household savings. It might be reflecting the proportional relationship between household disposable income and savings which means that as income rises; household savings also increases. This is in line with the empirical analysis by Arora and Vamvakidis (2005) which finds that a $1 \%$ point increase in per capita income growth raises the national saving rate by $1 \%$ in industrialized countries and $0.5 \%$ in developing countries. It may also reflect that as income increases, household savings also increases. The implication is that an increase in the growth of per capita income seems to be one of the best ways to raise the level of household savings in South Africa in the long run. These findings are consistent with the view held by Giovannini (1983) that only increases in transitory income raise savings. The relationship between current income and level of savings is consistent with the predictions of economic theory. That is, the marginal propensity to save will increase (sometimes at a decreasing rate) with income.

The coefficient of real GDP is also positive and significant (78.31). The implication is that it will have a positive and significant effect in the level of household savings. It appears that an increase in the level of real GDP will lead to an improvement in the level of household savings in South Africa. On the contrary, household debt coefficient of (-65.49) is negative and statisitcally significant. Horioka and Wan (2007) included the real interest rate to test for the impact of financial variables and expect its coefficient to be positive if the substitution effect is more than the income effect. In this case our coefficient is negative and the suspicion is that in the case of South Africa the substitution effect is less than the income effect.

The insignificant coefficient of the interest rates gives the impression that the level of interest has no signicant influence on household savings. This suggests either that income and substitution effects offset each other or that liquidity constraints weaken the effects of intertemporal relative prices on intertemporal consumption choices. The inflation rate is included as a proxy for the price uncertainty and macroeconomic stability. In Table 3, the results show that its coefficient is negative and statistically insignificant on household savings. Therefore, it appears that inflation rate does not have a huge and direct impact on the low levels of household savings in the South African economy. The estimated coefficient of foreign savings is positive and significant. These findings are in line with Schmidt-Hebbel et al. (1992).

Following Agung (2011), in order to obtain additional results or conduct further analysis of VECM, the VEC stability condition check of the VEC model is done (see Appendix 2 for results of the stability test). The graphical representation of the roots in Figure 1 illustrate the inverse roots of the AR characteristic polynomial and all the roots are inside the unit circle. The implication is that since there is no single root outside the unit circle, our VAR model satisfies the stability condition.

Figure 1. Inverse Roots of AR Characteristic Polynomial

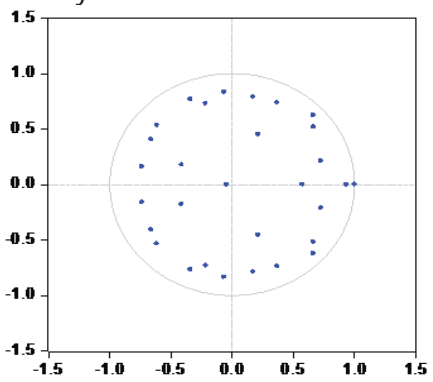

Clearly, this VEC model should be considered as acceptable in a statistical sense and as a result further analysis can be done. The estimated model also passed diagnostic tests of normally distribution, no autocorrelation, no ARCH and no heteroskedasticity at $5 \%$ significance level (Table 4).

Table 4. Diagnostic Checks Analysis

\begin{tabular}{l|ccc}
\multicolumn{1}{c|}{ Test for } & Test & p-value & Conclusion \\
\cline { 1 - 1 } Breuch-Godfrey Serial correlation & LM & 0.0552 & Accept $\mathrm{H}_{0}$ \\
Heteroskedasticity & ARCH LM & 0.531 & Accept $\mathrm{H}_{0}$ \\
Stability & White(no cross) & 0.6386 & Accept $\mathrm{H}_{0}$ \\
& RamseyRESET & 0.3141 & Accept $\mathrm{H}_{0}$
\end{tabular}


As far as normality test is concerned even though the p-value is smaller than $0.05 \%$ the histogram in Figure 2 indicates that the residuals may be normally distributed because if we mentally superimpose the bell-shaped normal distribution curve on the histogram, it gives an impression that a normal approximation may be appropriate. From the descriptive statistics the initial indication is that the residuals are not normally distributed based on the fact that normally distributed variable skewness should be zero and kurtosis 3 according to Gujarati and Porter (2009). Since the kurtosis exceeds 3 it means the distribution is peaked relative to the normal therefore, the histogram exhibits some degree of leptokurtosis ${ }^{3}$. The skewness is negative hence a slightly longer left tail and the series has an excess peak at -1 which is closer to the mean of 0.003 . Therefore, despite the initial observation we accept the null hypothesis of normal distribution because our descriptive statistics in Figure II is not very far from the expected values of normal distribution.

Figure 2. Histogram of Residuals

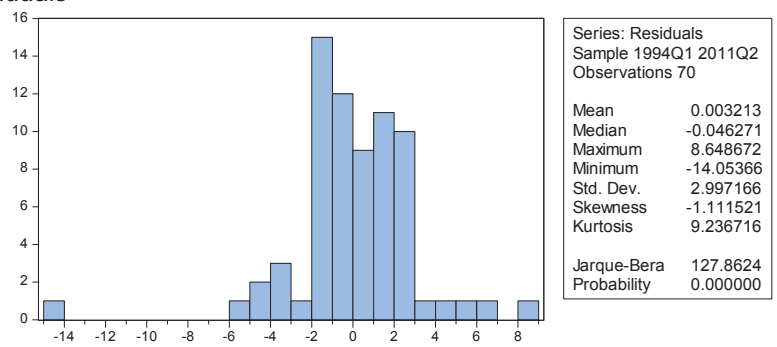

It is therefore evident enough that the specification of VECM is correct as none of the tests are rejecting the null hypothesis. The CUSUM test finds the parameter of our model to be stable because the cumulative sum goes inside the area between the two critical lines (see Figure 3). This movement inside the pair of 5\% critical lines suggests the coefficient stability on the CUSUM test. The test is therefore a clear indication of stability in the equation during the sample period.

Figure 3. CUSUM Test

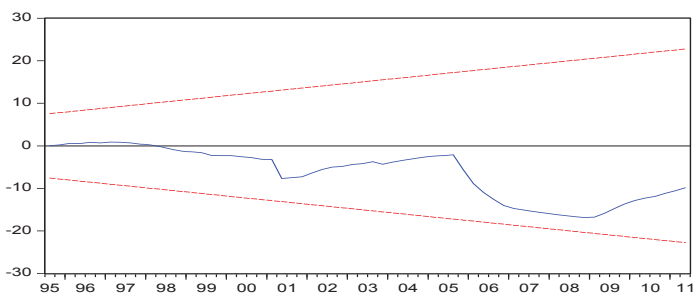

Figure 4. CUSUM of Squares

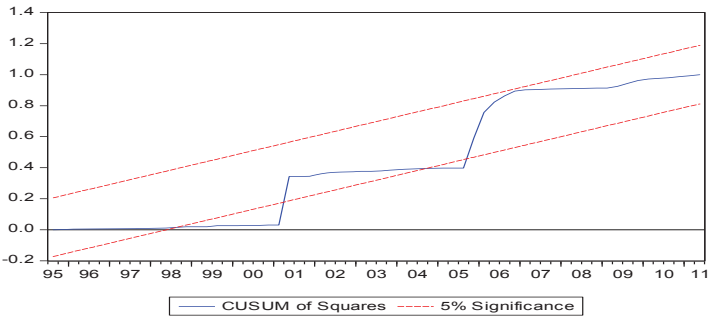

The CUSUM and CUSUMSQ test are giving us conflicting results. Figure 4 suggests a small amount of variance instability at the beginning and the middle of the period due to misspecification of the short run model. But, nevertheless the great movement is maintained inside the critical lines within the $5 \%$ significance lines throughout. Since our model

${ }^{3}$ Leptokurtosis is a common feature in economic or financial data that shows that the series tend to have an excess peak at the mean and rather fat tails in the distribution. 
performs well in all the tests, this allows us to go on with our analysis.

GIRF and variance decomposition will then be employed to examine dynamic relationships among the variables. Following Hurley (2010)'s approach this paper utilizes the GIRF analysis which was developed by Koop et al. (1996) and Pesaran and Shin (1998). Unlike the conventional impulse response method which employs a Cholesky decomposition of the positive definite covariance matrix of the shocks. The advantage is that GIRF does not require orthogonalisation ${ }^{4}$ of shocks. Since the resulting impulse responses are invariant to the ordering of the variables in the VAR, this approach gives unique and robust results. To attest to these advantages, numerous studies that employed this analysis have postulated that it is more powerful than the simple impulse response method (Warne, 2008; Mukuddem-Petersen et al., 2010; Peng et al., 2011, Kumar et al., 2012).

The results of the GIRF system are in a graphical form up to 10 quarters ahead (Figure 5). The period indicates how far in the future the reaction of the variables under study will prevail. It shows the response of variables to generalized one standard deviation (S.D.) innovations. The first impression from Figure 5 is that considering the response of variables to a one S.D. innovations in response of LHSAV to Generalized One S.D Innovations, is that it responds very significantly. Although the positive impact persisted throughout the forecast period, the magnitude of the effect slowed gradually, starting with the second quarter. It started to increase by the end of third quarter and persisted throughout the forecast period.

The responses of LHSAV to all other shocks are consistent with economic intuition. For example, the response to LHYD, LINTR and LGDP is positive even though LGDP starts being negative and zero after the fourth quarter and persists being positive but insignificant into the future. This implies that a change in the level of household savings may have a positive influence on economic growth. The responses of LINTR and LHYD are very significant. The implication is that the levels of household disposable income may have a serious impact on the levels of household savings and higher interest rates are favorable to household savings.

Figure 5. Generalized impulse response functions

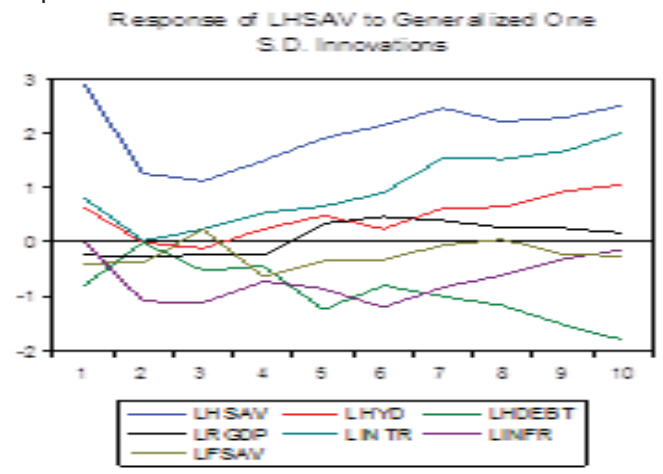

There is a huge positive association between LFSAV and LHSAV from the beginning of the forecast period up to the end of the third quarter. The positive impact persisted throughout the forecast period, but the magnitude of the effect slowed gradually up to the period 7 and starts to increase again and persisted throughout the forecast period. The outcome of the GIRF analysis is in line with the results of the VECM where the estimated coefficient of foreign savings is positive and significant.

Variance Decomposition tells us how much of a change in a variable is due to its own shock and how much of it is due to shocks to other variables. It also tells us the percentage of the fluctuation in a time series attributable to other variables at the 10 quarters time horizons. Table 5 presents the forecast of variance decomposition of the seven endogenous variables. The variance decomposition measures the contributions of each type of shock to the forecast error variance and it also provides information about the relative importance of each random innovation (shock) in affecting the variables in the VAR. More specifically, it indicates the amount of information each variable contributes to the other variables in the VECM model.

${ }^{4}$ Two vectors are orthogonal if they are perpendicular i.e. if they form a right angle. In statistical analysis, independent variables that affect a particular dependent variable are said to be orthogonal if they are uncorrelated. 
Table 5. Variance Decomposition of LHSAV

$\begin{array}{ccccccccc}\text { Period } & \text { S.E. } & \text { LHSAV } & \text { LHYD } & \text { LHDEBT } & \text { LRGDP } & \text { LINTR } & \text { LINFR } & \text { LFSAV } \\ 1 & 2.917064 & 100.0000 & 0.000000 & 0.000000 & 0.000000 & 0.000000 & 0.000000 & 0.000000 \\ 2 & 3.424505 & 86.02505 & 0.746147 & 0.335980 & 0.087327 & 0.827573 & 9.138538 & 2.839388 \\ 3 & 3.873840 & 75.60921 & 1.495243 & 3.440151 & 0.307670 & 0.777256 & 16.15054 & 2.219927 \\ 4 & 4.332097 & 72.37840 & 1.240621 & 2.864949 & 0.259756 & 0.813557 & 16.66627 & 5.776446 \\ 5 & 5.019939 & 68.25227 & 0.943479 & 6.028884 & 2.560913 & 0.862926 & 16.88622 & 4.465308 \\ 6 & 5.810176 & 64.63353 & 0.875806 & 5.373112 & 4.816875 & 1.243030 & 19.38074 & 3.676906 \\ 7 & 6.572770 & 64.44963 & 0.703159 & 4.550684 & 4.976971 & 3.063338 & 19.37228 & 2.883936 \\ 8 & 7.158632 & 63.88953 & 0.645883 & 4.674982 & 4.851815 & 4.685164 & 18.77965 & 2.472976 \\ 9 & 7.726988 & 63.57721 & 0.881078 & 5.284983 & 4.566531 & 6.181365 & 17.38131 & 2.127518 \\ 10 & 8.400442 & \mathbf{6 2 . 7 3 8 3 0} & 1.127113 & 6.228490 & 4.114639 & 8.372475 & 15.58966 & 1.829316\end{array}$

The column labeled S.E in Table 5 represents the forecast error of the variable for each forecast horizon (period). The forecast error emanates from the variation in the current and future values of the shocks to each variable in the system. The reported numbers in the remaining columns give the percentage of the forecast error in the household savings that can be contributed to innovations in the household savings itself and other variables at ten different time periods. Each row adds up to the value of a $100 \%$. From the table we realize that own shocks variation ranged from $62.7 \%$ to $100 \%$ over the ten quarters period of forecast. This implies that from a contribution of $100 \%$ to variations in its forecast errors, the contribution of household savings fell to $68.3 \%$ in the medium term and $62.7 \%$ in the long term. The difference was therefore taken up by other variables. At period 1 LHSAV is $100 \%$ because the only source of the one period ahead variation is its own shock.

In addition, the results reveal that after household savings itself, inflation rate is the most significant group for the error variance. Starting from the tenth quarter, their shocks account for more than $15.6 \%$ in explaining the variance in household savings. The contributions of innovations in inflation rate increased from the first to the seventh quarter and decreased gradually to the last quarter. It moved from $9.2 \%$ to almost $16 \%$ which is a significant increase from period to period. In the same breath, the gradual increase can be seen in the contribution of GDP and interest rate. Their contributions however remain small compared to that of inflation rate in explaining how household savings may tend to be affected if there was a possible shock in one of the variables. Household debt appears to be third in line in terms of contribution of innovation to household savings. Its contributions increase from the $1^{\text {st }}$ to the $3^{\text {rd }}$ period and gradually decline to the $10^{\text {th }}$ period. The contribution of innovation in foreign savings to the variance of household savings is also small but bigger than that in GDP and interest rate from the $1^{\text {st }}$ to the $5^{\text {th }}$ period where it is starting to decline gradually towards the end. Also worth noticing is the fact that the smallest contribution to the variance of household savings is made by household disposable income. Its contribution increases from the $1^{\text {st }}$ period to the $3^{\text {rd }}$ and gradually decreases towards the end with only $0.65 \%$ contribution in the long run.

In summary, the variance decomposition analysis shows that "own shocks" constitute the predominant source of variations in household savings in South Africa. The analysis further seems to suggest that the household savings can be explained by the disturbances in the macroeconomic variables used in this study. Finally all the variables can be regarded as endogenous to the system because Sbeiti and Hadadd (2011) maintain that if the shocks do not explain any of the forecast error variance of one macroeconomic variable in all forecast horizons, then this variable is exogenous. At the same time if it happens that shocks can explain all the forecast error variance of the variable at all forecast horizons, this variable is an entirely endogenous variable.

\section{Discussion, Conclusions, Policy Implications and Future Scope}

The household savings model for South Africa was based on the Keynesian saving function, a complement of the consumption function. The methodology included testing of time series properties of data by employing both the visual inspection and the stationarity tests, estimation of long run household savings function by using the Johansen and Juselius cointegration and a parsimonious stable VECM. The model was also taken through a battery of both diagnostic and stability tests. The diagnostic tests included among others the test of no serial correlation by Breusch and Godfrey (1978) and White (1980) test of heteroskedasticity. To test for the stability of the model we applied Brown et al. (1975)'s CUSUM and CUSUM of squares tests. The VEC stability condition check of the VECM was also done and the dynamic effect of the model was further analyzed by the GIRF and the variance decomposition. 
The study concludes that household savings can be improved by a higher level of disposable income and higher economic growth. The results have shown that the rate of household savings is correlated with disposable income and real GDP is positive and significant. The analysis indicates that there is a negative long run relationship between household savings and interest rate. This is caused by the insignificant coefficient of interest rate and the conclusion is that this variable has no significant influence on household savings in South Africa. Inflation rate was included in this paper as a proxy for the price uncertanity and macroeconomic stability. Even though we have established that it has positive relationship with the dependent variable, we concluded that it does not have a huge and direct influence because it is staistically insignificant. Our results have shown that household debt has a huge influence on the level of household savings. It has been confirmed by the fact that there is a negative relationship between household debt and household savings.

The main objective of this paper was to utilize time series data to run regressions in identifying the determinants that affect household savings in the South African economy. GIRF was employed to examine dynamic relationships among the variables and the variance decomposition analysis was used to estimate variables which mostly contribute in explaining the shocks in household savings.

Empirical literature has also proved that national savings and growth are positively associated. In terms of causality, the research on the determinants of savings has generally considered growth as a determinant of national savings, suggesting that the causality runs from growth to national savings. Interest rate deregulation and the increased disposable income are expected to stimulate savings by households. In this context, it would be informative for policymakers to understand the recent trend in savings. The paper recommends that policies aimed at increasing the level of savings by households be further developed and adhered to. It is further recommended that government should consider reducing the income taxes as a way of improving the disposable income and rather increase consumption taxes. All these can be achieved by creating an enabling environment and also addressing barriers to savings, particularly those that affect the poorer individuals. Therefore, from the policymakers' perspective, an optimal combination of monetary and fiscal policies would go a long way in establishing a dynamic long run relationship between household savings and its determinants.

\section{References}

Adamopoulos, A.A., (2010). Financial Development and Economic Growth - An Empirical Analysis for Ireland. International Journal of Economic Sciences and Applied Research, 3, 75-88.

Agung, I.G.N., (2011). Time Series Data Analysis Using EViews. John Wiley \& Sons., New York.

Aktham, M., (2004). Oil price shocks and emerging stock markets: A generalized VAR approach. Internpplied Economtrics and Quantitative Studies, 1, 27-40.

Allen, F., \& Giovannetti, G., (2010). The effects of the financial crisis on Sub-Saharan Africa. Review of Development Finance, 1, 1-27.

Arora, V., \& Vamvakidis, A., (2005). The Implications of South African Economic Growth for the Rest of Africa: IMF Working Paper: African and European Departments. International Monetary Fund.

Aryeetey, E. (2004). Financing Africa's future growth and development: Some innovations. The intergovernmental group of twenty-four on international monetary affairs and development (G-24).

Asteriou, D., \& Hall, S., (2009). Applied econometrics: A modern approach using Eviews and Microfit revised edition. New York, Palgrave Macmillan.

Balchin, N. (2009). The Impact of the Global Financial Crisis in Africa. [Accessed February 2011].

Banerjee, A., Dolado, J., Galbraith, J.W., \& Hendry, D.F. (1993). Co-integration, error correction, and the econometric analysis of nonstationary data. Advanced texts in Econometrics. Oxford, Oxford University Press.

Breusch, T.S., (1978). Testing for autocorrelation in dynamic linear models. Australian Economic Papers, 17, 334-55.

Brown, R.L., Durbin, J., \& Evans, J.M. (1975). Techniques for testing the constancy of regression relations over time. Journal of the Royal Statistical Society, 37, 149-192.

Bureau of Economic and Business Affairs U.S. Department of State. (2002). Country reports on economic policy and trade practices.

Chitiga, M., Mabugu, R., \& Maisonnave, H., (2010). The impact of the economic crisis in South Africa: A computable general equilibrium model. In: AusAID-IFPRI-PEP Workshop on the impacts and policy responses to the global crisis, Darkar, Senegal.

Dickey, D.A., \& Fuller, W.A. (1979). Distribution of the estimators for autoregressive time series with a unit root. Journal of American Statistical Association, 74, 427-31.

Dickey, D.A., Jansen, D.W., \& Thornton, D.L. (1991). A Primier on Cointegration with an Application to Money and Income. Review Federal Reserve Bank of ST. Loius, 73, 58-78.

Elliot, G., Rothenberg, T.J., \& Stock, J.H. (1996). Efficient Tests for an Autoregressive Unit Root. Econometrica, 64, 813-836.

Giovannini, A. (1983). The interest elasticity of savings in developing countries: The existing evidence. World Development, 11, 601-607

Griffiths, W.E., Hill, R.C. \& Lim, G.C. (2008). Using EViews for Principles of Econometrics, John Wiley \& Sons, Inc., New York. 
Gujarati, D.N., \& Porter, D.C. (2009). Basic econometrics, Boston, Mc Graw-Hill.

Haavelmo, T. (1944). The Probability Approach in Econometrics. Econometrica, 12, iii-115.

Hoover, K.D., Johansen, S., \& Juselius, K., (2008). Allowing the data to speak freely: The macroeconometrics of the cointegrated vector autoregression. The American Economic Review, 98: 251-255.

Horioka, C.Y., \& Wan, J., (2007). The Determinants of Household Saving in China: A Dynamic Panel Analysis of Provincial Data. Journal of Money, Credit and Banking, 39, 2077-2096.

Hurley, D.T., (2010). A generalized impulse response investigation of U.S. long and short-term interest yields and Asian holdings of U.S. treasuries. Journal of International and Global Economic Studies, 3, 68-86.

Johansen, S., \& Juselius, K., (1990). Maximum likelihood estimation and inference on cointegration: With applications to the demand for money. Oxford Bulletin of Economics and Statistics, 52, 169-210.

Karolyi, G.A., (2002). Did the Asian financial crisis scare foreign investors out of Japan?. Pacific-Basi Finance Journal, 10, 411-442.

Koop, G., Pesaran, M.H., \& Potter, S.M., (1996). Impulse response analysis in nonlinear multivariate models. Journal of Econometrics, 74, 119-147.

Kulshreshtha, M., \& Parikh, J.K., (2000). Modeling demand for coal in India: vector autoregressive models with cointegrated variables. Elsevier Science, 25, 149-168.

Kumar, S., Managi, S., \& Matsuda, A., (2012). Stock prices of clean energy firms, oil and carbon markets: A vector autoregressive analysis. Elsevier Science.

Kwiatkowski, D., Phillips, P.C.B., Schmidt, P., \& Shin, Y., (1992). Testing the null hypothesis of stationarity against the alternative of a unit root: How sure are we that economic time series have a unit root? Journal of Econometrics, 54, 159-178.

Mahadeva, L., \& Robinson, P., (2004). Unit root testing to help model building, London, Bank of England.

Masilela, E., (2009). South African Savings linstitute chairman's statement at the occasion of the launch of savings month 2009. [Accessed March 2011].

McCarthy, C., (2009). The global financial and economic crisis and its impact on Sub-Saharan economies. [Accessed February 2011].

McLvor, K., (2009). Saving today for a better tomorrow. Consumer conference, Gallagher Convention Centre, Johannesburg, 19 June 2009.

Mukuddem-Petersen, J., Petersen, M.A., Bosch, T., \& De Waal, D., (2010). Response of subprime residential mortgage loan and mortgage-backed securities prices to financial shocks. 3rd IASTED African Conference. Gaborone, Botswana.

Ng, S., Perron, P., (2001). Lag Length Selection and the Construction of Unit Root Tests with Good Size and Power. Econometrica, 69, 1519-1554.

Peng, W.B., Tian,K., Tian, Y.H., \& Xiang, G.C., (2011). VAR analysis of foreign direct investment and environmental regulation: China's case. Business and Economic Horizons, 5, 13-22.

Pesaran, H.H. \& Shin, Y., (1998). Generalized impulse response analysis in linear multivariate models. Economics Letters, 58, 17-29.

Petersen, M.A., Senosi, M.C. \& Mukuddem-Petersen, J., (2012). Subprime Mortgage Models, New York, Nova Science Publishers.

Phillips, P.C.B., \& Perron, P., (1998)., Testing for a unit root in time series regression. Biometrika, 75, 335-346.

Pradhan, R.P., (2009). Education and economic growth in India: Using Error Correction Modelling. International Research Journal of Finance and Economics, 2.

Pradhan, R.P., (2011). Finacial development, growth and stock market development: The trilateral analysis in India. Journal of Quantitative Economics, 9.

Rufino, C.C., (2008). The Steady State Relationship and the Spread between Treasury Bill and Commercial Lending Rates. DLSU-AKI Working Paper Series. Manila: De La Salle University.

SARB., (2010). Annual Economic Report. Pretoria: South African Reserve Bank.

Sbeiti, W., Hadadd, A.E., (2011). Stock markets dynamics in oil-dependent economies: Evidence from GCC countries. International Research Journal of Applied Finance, 2, 205-250

Schmidt-Hebbel, K., Webb, S.B., \& Corsetti, G., (1992). Household Saving in Developing Countries: First Cross-Country Evidence. The World Bank Economic Review, 6, 529-547.

Sheng, H.C., \& Tu, A.H., (2000). A study of cointegration and variance decomposition among national equity indices before and during the period of the Asian financial crisis. Journal of

Multinational Financial Management, 10, 345-365.

Tiwari, A.K., (2011). Energy consumption, $\mathrm{CO}_{2}$ emissions and economic growth: A revisit of the evidence from India. Applied Econometrics and International Development, 11-2.

Warne, A., 2008., Generalized Impulse Responses. Retrieved from

http://www.texlips.hypermart.net/download/generalized-impulse-response.pdf

White, H., (1980). A heteroskedasticity-consistent covariance matrix estimator and a direct test for heteroskedasticity. Econometrica, 48, 817-838.

\section{Appendix 1: Summary of Data Preparation}

\begin{tabular}{|c|c|c|}
\hline Variables/Data* & Data From Source & Attuned Data \\
\hline 1. Household savings & Current prices seasonally adjusted quarterly data & \\
\hline
\end{tabular}




\begin{tabular}{|l|l|l|}
\hline & measured in millions & \\
\hline $\begin{array}{c}\text { 2. Household } \\
\text { disposable income }\end{array}$ & $\begin{array}{l}\text { Current prices seasonally adjusted quarterly data } \\
\text { measured in millions }\end{array}$ & \\
\hline $\begin{array}{c}\text { 3. Household debt to } \\
\text { disposable income }\end{array}$ & $\begin{array}{l}\text { Current prices seasonally adjusted quarterly data } \\
\text { measured in millions }\end{array}$ & $\begin{array}{l}\text { Constant 2005 prices. Seasonally adjusted at } \\
\text { annual rate. Quarterly data measured in millions }\end{array}$ \\
\hline 4. Real GDP & Monthly data & Averaged to quarterly data \\
\hline $\begin{array}{l}\text { 5. Interest rate or } \\
\text { Prime overdraft }\end{array}$ & Monthly data. Percentage change over 12 months & Averaged to quarterly data \\
\hline 6. Inflation rate & $\begin{array}{l}\text { Seasonally adjusted at annual rate. Quarterly data } \\
\text { measured in millions }\end{array}$ & $\begin{array}{l}\text { A combination of Change in liabilities related to } \\
\text { reserves and Change in capital transfer account } \\
\text { and financial accounts including unrecorded } \\
\text { transactions }\end{array}$ \\
\hline
\end{tabular}

*SARB data tables are available at http://www.sarb.co.za

Appendix 2: VEC stability condition check

Roots of characteristic polynomial

Endogenous variables: LHSAV LHYD LHDEBT LRGDP LINTR LINFR LFSAV

Exogenous variables:

Lag specification: 14

Date: 04/21/12 Time: 15:49

\begin{tabular}{|c|c|}
\hline Root & Modulus \\
\hline $1.000000-1.63 e-15 i$ & 1.000000 \\
\hline $1.000000+1.63 e-15 i$ & 1.000000 \\
\hline 1.000000 & 1.000000 \\
\hline 1.000000 & 1.000000 \\
\hline 1.000000 & 1.000000 \\
\hline 1.000000 & 1.000000 \\
\hline 0.931652 & 0.931652 \\
\hline $0.661229+0.623414 i$ & 0.908773 \\
\hline $0.661229-0.623414 i$ & 0.908773 \\
\hline $0.664868-0.517907 i$ & 0.842779 \\
\hline $0.664868+0.517907 i$ & 0.842779 \\
\hline$-0.339369+0.768364 i$ & 0.839973 \\
\hline$-0.339369-0.768364 i$ & 0.839973 \\
\hline$-0.068364+0.834475 i$ & 0.837271 \\
\hline$-0.068364-0.834475 i$ & 0.837271 \\
\hline $0.367920+0.735730 i$ & 0.822595 \\
\hline $0.367920-0.735730 \mathrm{i}$ & 0.822595 \\
\hline$-0.615931-0.532854 i$ & 0.814435 \\
\hline$-0.615931+0.532854 i$ & 0.814435 \\
\hline $0.172498-0.788794 i$ & 0.807435 \\
\hline $0.172498+0.788794 i$ & 0.807435 \\
\hline$-0.661607-0.407545 i$ & 0.777057 \\
\hline$-0.661607+0.407545 i$ & 0.777057 \\
\hline$-0.215221-0.730487 i$ & 0.761533 \\
\hline$-0.215221+0.730487 i$ & 0.761533 \\
\hline$-0.738087+0.160658 i$ & 0.755369 \\
\hline$-0.738087-0.160658 i$ & 0.755369 \\
\hline $0.724351+0.213096 i$ & 0.755046 \\
\hline $0.724351-0.213096 i$ & 0.755046 \\
\hline 0.574051 & 0.574051 \\
\hline $0.213430+0.453335 i$ & 0.501064 \\
\hline $0.213430-0.453335 i$ & 0.501064 \\
\hline$-0.412875-0.175810 i$ & 0.448748 \\
\hline$-0.412875+0.175810 i$ & 0.448748 \\
\hline-0.046218 & 0.046218 \\
\hline
\end{tabular}

VEC specification imposes 6 unit root(s). 